\title{
Perfil do absenteísmo em um banco estatal em Minas Gerais: análise no período de 1998 a 2003
}

\author{
Absenteeism profile in a state bank in M inas Gerais \\ between 1998 a 2003
}

\author{
Luiz Sérgio Silva ${ }^{1}$ \\ Tarcísio $M$ árcio $M$ agalhães Pinheiro ${ }^{1}$ \\ Emília Sakurai ${ }^{2}$
}

${ }^{1}$ Departamento de M edicina Preventiva e Social FaculdadedeM edicina, UniversidadeFederal de M inas Gerais. Av. Prof. Alfredo Balena 190, Santa Ephigênia. 30130-100 Belo Horizonte M G. luizsergios@yahoo.com.br

${ }^{2}$ Departamento de

Estatística, Instituto de

Ciências Exatas,

Universidade Federal de

M inas Gerais.
Abstract The purpose of this paper was to study the profile of absenteeism in a state bank and to establish the more frequent causes for sick leaves among the members of the staff. A cross-cut, de scriptiveand quantitative study was developed for approaching absenteeism and its most frequent causes in a state bank in the state of $\mathrm{M}$ inas Gerais between 1998 and 2003. The absenteeism rates were homogenous, with a decrease during the period of the study, except for the frequency rates, as a result of alterations in their numerators and denominators. The prevalence of musculoskeletal diseases and mental disorders was of 33,25 and 22,21 leaves per 1,000 workers respectively. Leaves of women and workers in relatively low-pay positions, aged between 40 and 49, married, working in the institution for over 21 years predominated. The study indicated that sick leaves due to musculoskeletal diseases that where predominating be fore in the company are decreasing. On the other hand, therewas an increase of cases of mental and behavioral disorders, indicating a possible change in the health profile. However, further studies will be necessary to corroborate these results. Key words Absenteeism, Musculoskeletal diseases, M ental and behavioral disorders, Bank work
Resumo 0 objetivo dessa pesquisa foi estudar 0 perfil do absenteísmo em uma empresa bancária estatal eestimar a prevalência deafastamentos pelas doenças que mais acometeram seus trabalhadores. Foi realizado um estudo transversal, descritivo e quantitativo abordando absenteísmo e prevalência de causas de afastamento em um banco estatal no estado de M inas Gerais, no período de 1998 a 2003. O síndices de absenteísmo apresentaram distribuição heterogênea, estando em queda no período estudado, exceto a taxa de freqüência, devido a modificações nos números que compõem seus numeradores e denominadores. As prevalências das doenças osteomusculares e dos distúrbios mentais e comportamentais foram 33,25 e 22,21 afastamentos por 1.000 trabal hadores, respectivamente. H ouve predomínio de afastamentos detrabalhadores do sexo feminino, com idade entre $40 \mathrm{e}$ 49 anos deidade, com tempo de empresa superior a 21 anos e com funções com menores valores de remuneração. 0 estudo indicou que as doenças osteomusculares e do tecido conjuntivo que antes predominavam na empresa estão em queda. H ouvetambém ascensão dos distúrbios mentais e comportamentais, indicando possível mudança no perfil de adoecimento. M ais estudos são necessários para a explicação dos resultados observados. Palavras-chave Absenteísmo, Distúrbios osteomusculares, Transtornos mentais e do comportamento, Trabalho bancário 
Introdução

Os trabalhadores compartilham os perfis de adoecimento e morte da população em geral em função de variáveis como idade, gênero, grupo social e outros, além daqueles derivados de sua inserção em um grupo específico de risco relacionado à sua atividade laborativa ${ }^{1}$. Nas últimas décadas, o setor bancário brasileiro vem passando por um processo de transformação sem precedentes, conhecido como reestruturação produtiva, através do trinômio demissões em massa, automação eterceirização, levando os bancários a viverem um modo singular de instabilidade e intensificação do trabalho $0^{2,3}$.

Esse cenário tem implicado rápidas e profundas modificações no processo e na organização do trabalho e no perfil de adoecimento da categoria ${ }^{4,5}$. Todavia, existem poucos estudos que descreveram e analisaram essas mudanças, especialmente no setor financeiro brasileiro. A dificuldade de acesso a bancos de dados de empresas e de órgãos públicos tem se mostrado um dos grandes limitadores na produção científica desta questão.

O conhecimento do absenteísmo-doença em suas múltiplas determinações torna-se fundamental para a organização e planejamento das ações dos Serviços de A ten ção à Saúde do TrabaIhador ${ }^{6}$ e a determinação de seu perfil permite a identificação de excessos de ocorrências de casos de determinadas morbidades ${ }^{7}$. A decisão de avaliar os índices de absenteísmo partiu das dificuldades encontradas no diagnóstico da situação de saúde dos trabalhadores de um grande banco estatal no estado de M inas Gerais, além da observação preliminar de que a ocorrência de afastamentos por licenças-saúde indicavam mudança no perfil de adoecimento.

O objetivo central desta pesquisa foi estudar o perfil do absenteísmo nessa empresa, estimando a prevalência de afastamentos pelas doenças que mais acometeram seus trabal hadores e descrevendo a morbidade ao longo do tempo. 0 absenteísmo pode ser uma expressão do impacto negativo do trabalho na saúde dos trabalhadores, o que leva a conjeturar que ele, como um todo, e principalmente por motivo de doença, podeser apenas um sintoma de que al go não vai bem na relação capital/trabalho e, como tal, deve ser encarado ${ }^{3}$.
Material e métodos

Foi realizado um estudo transversal, descritivo e quantitativo, abordando absenteísmo e prevalência de causas de afastamento em um banco estatal no estado de M inas Gerais, no período de 1998 a 2003.

A população estudada foi composta do universo anual dos trabalhadores de um banco do setor público, distribuídos pelas suas 492 dependências no estado de M inas Gerais (agências e órgãos regionais). Um mesmo trabalhador podia ter produzido vários eventos, havendo, portanto, repetições.

Os dados sobre afastamentos foram fornecidos pela Caixa de Assi stência dos funcionários desse banco, queéuma empresa terceirizada responsável pela realização do programa de controle médico de saúde ocupacional do mesmo. Todos os afastamentos por licença-saúde são apresentados a essa Caixa, que realiza a avaliação da pertinência, registro, comunicação e estatística. Os afastamentos registrados foram disponibilizados aos pesquisadores sob a forma de arquivo no formato Access, contendo nome e matrícula do trabal hador, local de trabalho, período deafastamento ecodificação internacional de doenças, 10a revisão. A seguir, esses dados foram agrupados às informaç̧ões sociodemográficas obtidas no sistema de ARH (Administração de Recursos Humanos) da empresa, para a realização das análises estatísticas.

A pesquisa foi submetida, em sua fase de projeto, à aprovação do Comitê de Ética em Pesquisa da Universidade Federal de Minas Gerais (COEP), sendo aprovada e solicitada autorização da empresa para a utilização e divulgação dos dados e resultados.

Adotou-se o conceito de absenteísmo de causa médica da Organização Internacional do Trabalho ${ }^{8}$, ou seja, "o período de ausência laboral que se aceita como atribuível a uma incapacidade do indivíduo, exceção feita para aquela derivada de gravidez normal ou prisão". Entende-se por ausência laboral o período ininterrupto de falta ao trabalho, contado desde seu começo, independentemente de sua duração.

Utilizaram-se as recomendaç̃es do Subcomitê de Absentésmo da Sociedade Internacional de Saúde Ocupacional ${ }^{8}$, abordando-se os índices de freqüência, gravidade, percentual deabsentésmo e duração média das ausências, como indicadores de absenteísmo, representados pelas fórmulas: 
. Índice de freqüência $=\Sigma N^{\circ}$ de casos/ $N$ úmero de trabalhadores

. Índice de gravidade $=\Sigma$ Dias perdidos/ $\mathrm{N}$ úmero de trabalhadores

. Percentual de absenteísmo $=\Sigma$ Dias perdidos X $100 \Sigma /$ Dias trabalhados

. Duração média das ausências $=\Sigma$ Dias perdidos/ $\Sigma$ No 0 de casos

As prevalências de afastamentos foram abordadas por grupamentos da Codificação Internacional de Doenças, $10^{\text {a }}$ revisão $(\mathrm{CID} 10)^{9}$, sendo discriminados por morbidades específicas os maiores destaques em termos de dias perdidos (grupamentos V e XIII) e em número de ocorrências (grupamentos V eXIII, X eXIX) ${ }^{9}$, distribuídos, ainda, por sexo, idade, estado civil, escolaridade, tempo de empresa e função.

As variáveis dependentes foram o número de dias de afastamento e o número de eventos. Foram considerados afastamentos de curta duração aqueles de até cinco dias, de média duração entre seis e quinze dias e grandes afastamentos os superiores a dezesseis dias.

Como variáveis independentes, foram usadas: sexo, estado civil, escolaridade, idade, tempo de empresa, função e natureza médica do agravo.

Para a análise estatística, utilizou-se o pacote estatístico SPSS versão 11 (edição e análise).

A AN OVA (análise de variância) e o testet de Student foram empregados para a verificação das diferenças entre as médias da quantidade de dias de afastamento e do número de eventos, adotando-se como nível de significância alfa de $5 \%$.

\section{Resultados}

Entre 1998 e 2003, ocorreram, no banco estatal objeto deste estudo, 6.445 afastamentos, totalizando 302.893 dias de ausências ao trabalho. Esses afastamentos e respectivos números de dias foram produzidos por 2.386 trabalhadores, sendo de 8.156 pessoas a população de bancários que compôs o denominador desta pesquisa. Fizeram parte dela o conjunto de trabalhadores ativos, os afastados por licença de saúde e os aposentados durante o período de 1998 a 2003. Não houve perda de dados e um mesmo trabaIhador pode ter produzido vários eventos, havendo, portanto, repetições.

No grupo de funcionários presentes na empresa nesse período, houve predomínio de trabalhadores do sexo masculino $(60,43 \%)$, com média de idade de 40,16 anos, sendo a faixa etária predominante a de 40 a 49 anos (45,42\%).

Também predominaram os funcionários ca$\operatorname{sados}(66,60 \%)$. Em relação ao tempo de empresa, preponderou aquelegrupo com tempo deserviço entre 11 e 30 anos (68,95\%), com média de 15,61 anos de empresa.

Quanto ao grau de instrução, houve grande concentração de trabalhadores com curso superior $(41,37 \%)$; entre as funções, destacaram-se os escriturários $(37,41 \%)$, seguidos pelos caixas executivos (17,04\%).

Notaram-se al gumas mudanças no comportamento do absenteísmo na empresa com queda praticamente constante na maioria dos indicadores (número de dias de afastamento, percentual de absenteísmo, índice de gravidade e duração média das ausências), porém, com aumento do número de casos e do índice de freqüência (Tabela 2). Esse comportamento refere-se a uma população praticamente constante, com baixo rodízio de pessoal, com média de desligamentos e aposentadorias em torno de 31 e 26 por mês, respectivamente.

Quando se analisaram os afastamentos relacionando-os ao gênero, houve predomínio do sexo feminino, tanto em número de afastamentos $(56,97 \%)$ quanto em número de dias de afastamento (58,37\%). Na análise de afastamento por faixa etária, predominou a de 40-49 anos, responsável por $52,83 \%$ dos afastamentos e pelo mai or número de dias de afastamento $(58,84 \%)$. Em relação ao estado civil, o grupo dos casados foi o que mais se afastou do trabal ho $(62,64 \%)$.

Para a variável tempo de empresa, os afastamentos concentraram-se no grupo de trabalhadores com mais de 21 anos de empresa $(61,85)$. Considerando-se o nível de instrução, o grupo de afastamentos que mais se destacou foi o de indivíduos com formação superior ou mais $(69,70 \%)$, porém com significância estatística apenas para 0 número de dias de afastamento ( $p=.000)$.

Pode-se observar pela Tabela 3, que os escriturários $(44,93 \%, 50,99 \%)$, os assessores $(19,38 \%$, $41,67 \%)$, a gerência média $(16,72 \%, 31,20 \%$ ) e os caixas executivos $(13,81 \%, 51,37 \%)$ foram, nessa ordem, as funções predominantes em termos de afastamentos e de número de dias de afastamento, ambos com significância estatística.

Existem, também, grandes diferenças entre homens e mulheres quando se analisam as funções. A maior diferença ocorreu no caso da gerência geral de agência, com os homens ocupando $87 \%$ e as mulheres com apenas $13 \%$. Entre os escriturários, existiu também diferença conside- 
Tabela 1. Caracterização da população de trabalhadores do banco estatal. M inas Gerais, 2003.

População/características Número Percentual

Sexo

Masculino

4.929

Feminino

3.227

60,43

Faixa etária (em anos)

20-29

30-39

1.193

2.209

3.704

$40-49$

50-59

60 e +

Estado civil

Solteiro

Casado

Separado

Divorciado

Viúvo

Tempo de empresa

0 a 1

2 a 5

6 a 10

11 a 20

21 a 30

31 a 40

Grau de instrução

Sem formação

Fundamental

M édio

Superior incompleto

Superior completo

Pós-graduação

M estrado

Doutorado

Funções

Advogado

Analista de agência

Analista júnior/pleno/

sênior

Assessor

Assistente de agência

Assistente seg. trabalho

Auditores

Auxiliares de agência

Caixa executivo

Engenheiro-arquiteto

Escriturário

Gerente de administração

Gerente de agência

Gerência média

Instrutor

M édico

Operador de informática

Superintendente

Vantagens substituição rável: 45\% eram homens e 55\%, mulheres. Para a gerencia média, os homens responderam por $49,8 \%$ eas mulheres, por $50,2 \%$. D os caixas executivos, $51,6 \%$ eram homens. Na gerência de administração, homens e mulheres ocuparam cerca de $50 \%$ dos cargos, cada. N os cargos de assessoria, $42 \%$ estavam ocupados por homens.

Analisando-se as morbidades responsáveis pelos afastamentos (Tabela 4), destacam-se primeiramente as referentes ao sistema osteomuscular e tecido conjuntivo e, a seguir, as relacionadas aos transtornos mentais e comportamentais. N este estudo, esses dois agrupamentos da CID são os mais prevalentes e os que mais dias de afastamento do trabalho geraram $(55,7 \%$ e $19,28 \%$, respectivamente). As doenças do apareIho respiratório têm expressiva participação no número de afastamento (13,81\%), mas baixa contribuição quanto ao número de dias de afastamento $(1,36 \%)$. Quase todos $(99 \%)$ os afastamentos ocorreram com intervalo de até quinze dias.

As lesões, envenenamentos e algumas outras causas externas começam a ganhar destaque, principalmentequanto ao número dedias de afastamento (terceira causa).

Pelo realce dos grupamentos dos transtornos mentais e comportamentais (TMC) e dos distúrbios osteomusculares (DOTC)), a Tabela 5 oferecea possibilidade de realizarem-sealgumas comparações entre eles. Ambos apresentaram redução do número de dias de afastamento durante o período, bem como da representação percentual no total de dias. Considerando-se a representação percentual nos diversos anos, o grupamento DOTC apresentou queda (69,69\% em 1998 para $36,43 \%$ em 2003), enquanto o grupamento TM C apresentou aumento (15,19\% em 1998 para $23,10 \%$ em 2003). Para o número de eventos, 0 grupamento DOTC continuou apresentando queda (30,20\% em 1998 para 13,79\% em 2003), enquanto 0 grupamento TM C manteve-se estável (15,56\% em 1998 para 15,58 em 2003).

Os dois grupamentos apresentaram queda nas médias anuais da quantidade de dias de afastamento durante todo o período. Como a população semanteve estável no período, com média de 7.429 trabal hadores, considerando-se as médias da quantidade de afastamentos, 247 para o grupamento DOTC e 165 para o grupamento TM C, obteve-seprevalências de 33,25 e22,27 afastamentos por 1.000 trabalhadores, respectivamente. 
Tabela 2. Índices de absenteísmo em um banco estatal. Minas Gerais, de 1998 a 2003.

\begin{tabular}{cccccccc}
\hline Anos & População & $\begin{array}{c}\text { Dias de } \\
\text { afastamento }\end{array}$ & $\begin{array}{c}\text { Número } \\
\text { de casos }\end{array}$ & $\begin{array}{c}\text { Percentual de } \\
\text { absenteísmo }\end{array}$ & $\begin{array}{c}\text { Índice de } \\
\text { gravidade }\end{array}$ & $\begin{array}{c}\text { Índice de } \\
\text { freqüência }\end{array}$ & $\begin{array}{c}\text { Duração } \\
\text { média das } \\
\text { ausências }\end{array}$ \\
\hline 1998 & 7.021 & 100.765 & 765 & 3,93 & 14,35 & 10,90 & 131,72 \\
1999 & 7.517 & 53.711 & 827 & 1,96 & 7,16 & 11,00 & 64,95 \\
2000 & 7.566 & 34.487 & 950 & 1,25 & 4,56 & 12,56 & 36,30 \\
2001 & 7.558 & 54.464 & 1.379 & 1,97 & 7,20 & 18,25 & 39,50 \\
2002 & 7.411 & 34.492 & 1.516 & 1,28 & 4,65 & 20,46 & 22,75 \\
2003 & 7.499 & 24.974 & 1.008 & 0,93 & 3,36 & 13,44 & 24,78 \\
\hline
\end{tabular}

Tabela 3. Caracterização sociodemográfica dos afastamentos e número de dias de afastamento por licença saúde, em um banco estatal. Minas Gerais, de 1998 a 2003.

\begin{tabular}{|c|c|c|c|c|c|c|c|c|}
\hline \multirow{2}{*}{ População/características } & \multicolumn{4}{|c|}{ Número de afastamentos } & \multicolumn{4}{|c|}{ Número de dias de afastamentos } \\
\hline & Valor & Percentual & M édia & $P$ & Valor & Percentual & Média & $P$ \\
\hline \multicolumn{9}{|l|}{ Sexo } \\
\hline M asculino & 2.773 & 43,03 & 2,41 & & 126.081 & 41,63 & 45,47 & \\
\hline Feminino & 3.672 & 56,97 & 2,97 & .000 & 176.812 & 58,37 & 48,15 & .334 \\
\hline \multicolumn{9}{|l|}{ Faixa etária (em anos) } \\
\hline $20-29$ & 445 & 6,90 & 1,93 & & 3.696 & 1,22 & 8,31 & \\
\hline 30-39 & 1.436 & 22,28 & 2,68 & & 36.316 & 11,99 & 25,29 & \\
\hline $40-49$ & 3.405 & 52,83 & 2,84 & & 178.228 & 58,84 & 52,34 & \\
\hline $50-59$ & 1.137 & 17,64 & 2,72 & & 83.121 & 27,44 & 73,11 & \\
\hline $60 e+$ & 22 & 0,34 & 4,40 & .000 & 1.532 & 0,51 & 69,64 & .000 \\
\hline \multicolumn{9}{|l|}{ Estado civil } \\
\hline Solteiro & 1.768 & 27,43 & 2,17 & & 61.227 & 20,21 & 34,63 & \\
\hline Casado & 4.037 & 62,64 & 2,64 & & 210.432 & 69,45 & 52,13 & \\
\hline Separado & 23 & 0,36 & 3,22 & & 1.462 & 0,50 & 63,57 & \\
\hline Divorciado & 411 & 6,38 & 2,72 & & 22.833 & 7,54 & 55,55 & \\
\hline Viúvo & 206 & 3,20 & 2,45 & .000 & 6.939 & 2,30 & 33,68 & .000 \\
\hline \multicolumn{9}{|l|}{ Tempo de empresa } \\
\hline 0 a 1 & 75 & 1,16 & 1,56 & & 676 & 0,22 & 9,01 & \\
\hline 2 a 5 & 863 & 13,39 & 2,20 & & 8.649 & 2,86 & 10,02 & \\
\hline 6 a 20 & 2.142 & 33,24 & 2,95 & & 85.435 & 28,21 & 39,89 & \\
\hline $21 \mathrm{e}+$ & 3.365 & 52,21 & 2,76 & .000 & 208.133 & 68,72 & 61,85 & .000 \\
\hline \multicolumn{9}{|l|}{ Grau de instrução } \\
\hline Fundamental & 288 & 4,47 & 3,14 & & 13.844 & 4,57 & 48,07 & \\
\hline M édio & 1.665 & 25,83 & 2,78 & & 57.759 & 19,07 & 34,69 & \\
\hline Superior & 2.824 & 43,82 & 2,65 & & 80.354 & 26,53 & 28,45 & \\
\hline Pós-graduação & 1.111 & 17,24 & 2,63 & & 98.164 & 32,41 & 88,36 & \\
\hline M estrado/doutorado & 557 & 8,64 & 2,70 & .456 & 52.772 & 17,42 & 94,74 & .000 \\
\hline \multicolumn{9}{|l|}{ Funções } \\
\hline Assessores & 1.249 & 19,38 & 2,66 & & 52.043 & 17,18 & 41,67 & \\
\hline Auditores & 13 & 0,2 & 1,63 & & 77 & 0,03 & 5,92 & \\
\hline Caixa executivo & 890 & 13,81 & 2,53 & & 45.874 & 15,15 & 51,37 & \\
\hline Cargos técnicos & 121 & 1,88 & 2,37 & & 1.778 & 0,59 & 14,69 & \\
\hline Escriturário & 2.896 & 44,93 & 3,14 & & 154.436 & 50,99 & 53,38 & \\
\hline Gerência média & 1.078 & 16,72 & 2,32 & & 33.637 & 11,10 & 31,20 & \\
\hline Gerente de agência & 79 & 1,23 & 1,39 & & 1.752 & 0,58 & 22,18 & \\
\hline Gerente de administração & 49 & 0,76 & 1,63 & & 1.469 & 0,48 & 29,98 & \\
\hline Instrutor & 39 & 0,61 & 2,29 & & 8.291 & 2,73 & 212,5 & \\
\hline Vantagens subst. & 9 & 0,14 & 1,80 & & 454 & 0,15 & 950,44 & \\
\hline Operadores de informática & 22 & 0,34 & 2,20 & .000 & 3.082 & 1,02 & 140,09 & .000 \\
\hline Total & 6.445 & & & & 302.893 & & & \\
\hline
\end{tabular}


Tabela 4. Número de afastamentos e número de dias de afastamentos, por grupamentos da CID 10, num banco estatal. Minas Gerais, de 1998 a 2003.

\begin{tabular}{|c|c|c|c|c|}
\hline \multirow[t]{2}{*}{ CID 10} & \multicolumn{2}{|c|}{ № afastamentos } & \multicolumn{2}{|c|}{ № dias afastamento } \\
\hline & $n$ & $\%$ & $\mathrm{n}$ & $\%$ \\
\hline V - Transtornos mentais e comportamentais (F00-F99) & 991 & 15,38 & 58395 & 19,28 \\
\hline X - Doenças do aparelho respiratório (J00-J99) & 890 & 13,81 & 4109 & 1,36 \\
\hline $\begin{array}{l}\text { XIII - Doenças do sistema osteomuscular e do tecido } \\
\text { conjuntivo (M 00-M 99) }\end{array}$ & 1482 & 22,99 & 168697 & 55,70 \\
\hline $\begin{array}{l}\text { XIX - Lesões, envenenamentos e algumas outras } \\
\text { conseqüências de causas externas (S00-T98) }\end{array}$ & 454 & 7,04 & 12550 & 4,14 \\
\hline Outros & 2628 & 40,78 & 59142 & 19,52 \\
\hline Total & 6445 & 100,00 & 302893 & 100,00 \\
\hline
\end{tabular}

Tabela 5. Número de afastamentos e de dias de afastamento por licença-saúde, referentes aos grupamentos XIII e V da CID 10, num banco estatal. Minas Gerais, de 1998 a 2003.

\begin{tabular}{|c|c|c|c|c|c|c|c|c|c|c|c|c|}
\hline \multirow{5}{*}{ Anos } & \multicolumn{12}{|c|}{ Grupamentos da CID 10} \\
\hline & \multicolumn{6}{|c|}{$\begin{array}{l}\text { XIII - Distúrbios osteomusculares } \\
\text { e do tecido conjuntivo (DOTC) }\end{array}$} & \multicolumn{6}{|c|}{$\begin{array}{l}\text { V- Transtornos mentais } \\
\text { e do comportamento (TMC) }\end{array}$} \\
\hline & \multicolumn{3}{|c|}{ № de afastamentos } & \multicolumn{3}{|c|}{ № dias de afastamento } & \multicolumn{3}{|c|}{$\mathrm{N} \cong$ de afastamentos } & \multicolumn{3}{|c|}{ № dias de afastamento } \\
\hline & \multirow[t]{2}{*}{$\mathrm{n}$} & \multicolumn{2}{|c|}{$\%$} & \multirow[t]{2}{*}{$\mathrm{n}$} & \multicolumn{2}{|l|}{$\%$} & \multirow[t]{2}{*}{$\mathrm{n}$} & \multicolumn{2}{|c|}{$\%$} & \multirow[t]{2}{*}{$\mathrm{n}$} & \multicolumn{2}{|c|}{$\%$} \\
\hline & & No total & No ano & & No total & No ano & & No total & No ano & & No total & No ano \\
\hline 1998 & 242 & 16,33 & 30,20 & 70.224 & 41,63 & 69,69 & 119 & 12,01 & 15,56 & 15.307 & 26,21 & 15,19 \\
\hline 1999 & 224 & 15,11 & 27,09 & 29.567 & 17,53 & 55,05 & 107 & 10,80 & 12,94 & 10.148 & 17,38 & 18,89 \\
\hline 2000 & 189 & 12,75 & 19,89 & 16.194 & 9,60 & 46,96 & 137 & 13,82 & 14,42 & 6.579 & 11,27 & 19,08 \\
\hline 2001 & 386 & 26,05 & 27,99 & 28.514 & 16,90 & 52,35 & 222 & 22,40 & 16,10 & 11.976 & 20,51 & 21,99 \\
\hline 2002 & 302 & 20,38 & 19,92 & 15.100 & 8,95 & 43,78 & 249 & 25,13 & 16,42 & 8.615 & 14,75 & 24,98 \\
\hline 2003 & 139 & 9,38 & 13,79 & 9.098 & 5,39 & 36,43 & 157 & 15,84 & 15,58 & 5.770 & 9,88 & 23,10 \\
\hline Total & 1.482 & 100,00 & 22,99 & 168.697 & 100,00 & 55,70 & 991 & 100,00 & 15,38 & 58.395 & 100,00 & 19,28 \\
\hline
\end{tabular}

Tabela 6. Prevalência por 1000 trabalhadores, número de afastamentos e de dias de afastamentos, conforme os grupamentos V e XIII da CID 10, num banco estatal. M inas Gerais, 1998 a 2003.

\begin{tabular}{|c|c|c|c|c|c|c|c|c|}
\hline \multirow{2}{*}{ Anos } & \multicolumn{4}{|c|}{$\begin{array}{l}\text { V- Transtornos mentais e } \\
\text { comportamentais (TMC) }\end{array}$} & \multicolumn{4}{|c|}{$\begin{array}{l}\text { XIII - Distúrbios osteomusculares e } \\
\text { do tecido conjuntivo (DOTC) }\end{array}$} \\
\hline & $\mathrm{n}$ & № de dias & M édia & Prev & $\mathrm{n}$ & № de dias & M édia & Prev \\
\hline 1998 & 119 & 15.307 & 128,63 & 16,95 & 242 & 70.224 & 290,18 & 34,47 \\
\hline 1999 & 107 & 10.148 & 94,84 & 14,23 & 224 & 29.567 & 132,00 & 29,80 \\
\hline 2000 & 137 & 6.579 & 48,02 & 18,11 & 189 & 16.194 & 85,68 & 24,98 \\
\hline 2001 & 222 & 11.976 & 53,95 & 29,37 & 386 & 28.514 & 73,87 & 51,07 \\
\hline 2002 & 249 & 8.615 & 34,60 & 33,60 & 302 & 15.100 & 50,00 & 40,75 \\
\hline 2003 & 157 & 5.770 & 36,75 & 20,94 & 139 & 9.098 & 65,45 & 18,54 \\
\hline Total & 991 & 58.395 & 58,93 & - & 1.482 & 168.697 & 113,83 & - \\
\hline
\end{tabular}


Ainda comparando-se os dois grupamentos, os afastamentos com intervalos superiores a noventa dias representaram $88 \%$ no grupamento do DOTC e $80 \%$ no TMC.

Quanto aos subgrupos de doenças do grupamento DOTC que acometeram os trabalhadores da empresa no período, os transtornos musculares, das sinóvias e dos tendões (M 60) totalizaram $80 \%$ (125.743) da quantidade de dias deafastamentos, seguidos pelas lombal gias e cervicalgias ( M 50) com quase 14\% (24.206). Quando se considerou o número de eventos, os transtornos musculares, das sinóvias e dos tendões (M 60) representaram 57\% (846) dos afastamentos e as lombal gias e cervicalgias (M 50) $25 \%$ (368), restando aos demais subgrupos o percentual aproximado de $18 \%$.

Os subgrupos que se destacaram no grupamento TMC foram os transtornos do humor F30, com $55,27 \%$ da quantidade de dias de afastamentos e $45,41 \%$ dos afastamentos, e os transtornos neuróticos relacionados ao estresse etranstornos somatoformes $F 40$, com $31,77 \%$ dos dias de afastamentos e $44,40 \%$ dos afastamentos.

\section{Discussão}

Neste estudo, ocorreram dificuldades para a obtenção de outras informações referentes à saúde, organização do trabalho e recursos humanos da empresa, o que limitou as possibilidades de infe rências explicativas para as mudanças e alterações verificadas durante o período de análise.

N ogueira eAzevedo ${ }^{10}$ sugeriram que os estudos epidemiológicos que permitem conhecer as diferentes variáveis que afetam o absenteísmo (como sexo, idade, estado civil, entre outros) podem auxiliar na prevenção do absenteísmodoença, na medida em que ajudam na elucidação de possíveis causas, e sugerir soluções.

Na atualidade, existecrescenteaumento da força detrabal ho feminina na categoria de bancários. Segundo o DIEESE², em pesquisa realizada entre 1986 e 1997, a participação feminina na categoria aumentou. Em 1986, elas representavam 36\% dos bancários, atingindo 42\% em 1994. Já em 1997, eram $47 \%$. N essa empresa pesquisada, a população feminina representava $40 \%$ dos trabalhadores. Em relação às funções, apesar do avanço no sentido da igualdade desua distribuição, ainda existe o predomínio do sexo masculino na ocupação das funções gerenciais de mais poder e melhores remunerações ${ }^{11,12}$. N essa empresa, as mulheres ocupam cerca de $20,7 \%$ das funções gerenciais.
A variável sexo érealçada na literatura, principalmente a partir da discussão do porquê das mulheres seafastarem mais ${ }^{6,13,14}$. No presenteestudo, corroborou-se esse fenômeno e constatou-se a real diferença entre os sexos quanto ao se afastar do trabalho por motivo delicença-saúde, principalmente em relação ao número de afastamentos. Os afastamentos de indivíduos do sexo feminino representaram $56 \%$ dos eventos, consumindo $58 \%$ do número de dias de afastamento.

Além das inferências apontadas pela literatu$\mathrm{ra}^{15}$, acrescentam-se as diferenças entre os cargos ocupados nessa empresa. $\mathrm{N}$ as funções nas quais houve mai or índice de afastamentos, como entre os escriturários e os assessores, havia predominância das mulheres. Há que se ressaltar, ainda, que essas funções são submetidas às altas pressões do ponto de vista ergonômico ${ }^{16}$.

Este estudo constatou, também, que quanto mais idade tinha o trabalhador bancário dessa empresa, mais ele se afastou. Tanto o número de ocorrências quanto o número de dias de afastamentos foi maior na faixa etária de 40-49 anos de idade, o que era de se esperar, haja vista ser essa a faixa etária predominante entre os trabaIhadores da empresa durante o período considerado no estudo. Não foram obtidos dados da literatura entre bancários para comparação e, em dados levantados em outros setores, como o da indústria e o hospitalar, alguns autores ${ }^{13,17}$ relatam que quanto mais jovem o trabalhador, mais ele se afasta do trabalho.

A empresa demitiu mais de 50.000 trabal hadores em todo o país de julho de 1995 até o final do ano de 1998 (para Minas Gerais, esse dado não foi obtido). Só voltou a realizar concursose contratações no final do ano de 1999, assim mesmo para admissões a partir de 2000 e com política restritiva, apenas de substituição do efetivo desligado e aposentado. Essa atitude permitiu 0 aumento da média deidade que, no período pesquisado, foi de 40 anos entre os presentes na empresa, enquanto que entre os bancários do país, a faixa etária predominante situava-se entre 25 e 40 anos de idade ${ }^{18}$.

A observação do fator tempo de trabalho mostrou que tanto a quantidade de dias de afastamento quanto o número de afastamentos apresentaram concentração entre os trabalhadores com mais deseis anos deempresa $(96,93,85,25 \%$, respectivamente) eprincipalmente entre aqueles com mais de 21 anos de empresa $(68,72,52,21 \%$, respectivamente). N ovamente não foram conseguidos dados sobretrabalhadores bancários para a comparação. Em outros setores, como o da 
indústria, o trabalhador com menos tempo de empresa é aquele que mais se ausenta do trabaIho ${ }^{10,19}$. No caso do banco estatal em estudo, a hipóteseéde quea existência deum período probatório de noventa dias e de um grande contingente de candidatos classificados nos concursos aguardando ser contratado seja o motivo principal pelo qual o trabalhador com menos tempo de serviço na empresa, portanto, menos estável, evite se afastar do trabalho.

Analisando-se conjuntamente as variáveis idade e tempo de empresa, os resultados reforçaram a hipótese de que o envelhecimento dessa população de trabalhadores bancários associado ao seu maior tempo de exposição aos riscos ocupacionais explicam melhor a maior ocorrência de afastamentos por licença-saúde observada nas faixas etárias mais elevadas.

0 estudo também demonstrou que, quando se considerou o estado civil do trabalhador, os casados afastaram-se por mais dias que os solteiros ( $69,45 \%$ e $20,21 \%$, respectivamente). Alguns autores ${ }^{20,14}$ relatam que 0 estado civil é fator de grande influência nos níveis de absenteísmo, principalmente quando o trabal hador possui filhos. Fischer ${ }^{19}$ descreveu que um grande absenteísmo é observado entre os casados quando associados a um grande número de dependentes. Na população de bancários dessa empresa, $67 \%$ eram casados e $28 \%$, solteiros. A maior quantidade de afastamentos é coincidente com esse predomínio de casados na população detrabalhadores, conforme relatado pela literatura.

O grau de instrução influenciou marcantementea ocorrência de afastamentos entre os funcionários dessa empresa. Os trabalhadores com nível superior ou mais geralmente mantêm-se afastados por maior período - as médias aumentam proporcionalmente ao grau de instrução.

Segnini ${ }^{4}$ diz que a categoria bancária distingue-se, há muito tempo, de outras categorias profissionais no Brasil, por ser altamente escolarizada, crescendo, na conjuntura atual, o número de bancários com terceiro grau completo e decrescendo a percentagem daqueles com apenas primeiro e segundo graus. M esmo não fazendo parte das exigências do conteúdo próprio de trabaIho, o grau de escolaridadeé cada vez mais elevado. N essa empresa, $42 \%$ dos trabalhadores possuem curso superior completo contra apenas $32 \%$ dos que detêm apenas o ensino médio.

Ao se analisarem os níveis de escolaridade relativamente à idade dos trabal hadores, percebe-se que os trabal hadores mais velhos possuem mais escolaridade: funcionários com escolarida- de de nível superior chegam a $51 \%$ entre aqueles na faixa etária entre 40 e 49 anos deidade, o mesmo acontecendo com os pós-graduados.

Quando comparados escolaridade e tempo de empresa, o comportamento é semelhante ao verificado quando se comparou a idade do trabalhador e a escolaridade. Cerca da metade dos que têm entreseis evinteanos deempresa possui escolaridade superior ou mais.

0 presente estudo é concordante, pelo menos em parte, com a literatura, quando se aborda a questão função exercida $a^{6,14,21}$. Os trabalhadores nas funções menos categorizadas, como os escriturários, foram os que mais se afastaram, tanto em número de eventos (aproximadamente $45 \%$ ) quanto em número de dias de afastamentos (aproximadamente 51\%). São seguidos por outras funções que, apesar de comissionadas, como os cargos de assistentes ecaixas executivos, recebem os menores valores na referência (comissão) da carreira nesse banco. N ota-se também mudança no perfil das atividades exercidas pelo bancário que, com o advento da reestruturação produtiva no setor, passa a ser um funcionário polivalente, comprometido com a organização, de alta qual ificação técnica, participação criadora, capaz de realizar atividades administrativas, gerenciais, além de ter que ser um excelentevendedor.

Voltando o olhar para os agravos que acometeram os trabalhadores da empresa, principalmente as doenças do sistema osteomuscular, em queda durante todo o período, poder-se-ia, então, pensar queestaria havendo mudança para melhor nas condições de trabalho nessa empresa, o queseria responsável pela redução na quantidade de dias de afastamento e, por conseqüência, nos números do absenteísmo. Isso traduz uma simplificação não cabível nessecaso, principalmentequando seleva em conta queo número de afastamento não foi homogêneo, até aumentou para algumas doenças.

Dos indicadores de absenteísmo abordados, a freqüência elevou-se, devido basicamente ao aumento do número de afastamentos, uma vez que no período analisado houve estabilidade no seu denominador, isto é, no número de trabaIhadores. Ele tem grande importância, tendo em vista que, apesar da redução da média de dias de afastamentos no período do estudo, o número de afastamentos por trabalhador aumentou. É, portanto, indicativo de que mais trabalhadores estão adoecendo e se afastando.

Diante desse cenário, pode-se levantar algumas questões: estaria havendo melhoria das con- 
dições de trabalho? Estaria em curso uma política de redução dos grandes afastamentos, com dezesseis ou mais dias?

Seria bastanteincoerente, então, acreditar que as condições de trabalho estariam melhorando significativamente, uma vez que o número de afastamentos continua aumentando. A empresa adotou, durante a década de noventa, programas agressivos de adequação e redução de seu quadro de pessoal, diminuindo seu contingente em mais de 50.000 trabalhadores. Somente no mês de julho de 1996, o banco demitiu em torno de 14.000 trabalhadores. Nessa mesma década, os salários permaneceram congelados, só retomando al guma reposição salarial no final do ano de2003.

$\mathrm{Na}$ realidade, a única mudança expressiva ocorrida na empresa no início desse período foi a implantação progressiva, a partir de 1997, do novo mobiliário, com características mais adequadas do ponto de vista ergonômico, apesar de se ter em conta, conforme informa a literatura, que as doenças do trabalho vinculadas ao sistema osteomuscular são de origem multifatorial 22-24.

Quanto à política de redução do número de dias de afastamentos, a empresa faz acompanhamento direto dos grandes afastamentos, gerenciando junto à Previdência Social para que se aposentem funcionários com mais de dois anos de afastamento e sem perspectivas de retorno. Os trabal hadores em condições de serem reabilitados retornaram à atividade após a reorientação de suas funções e adequação de suas condições de saúde.

O bservando-se os distúrbios mentais e comportamentais, pela alta prevalência apresentada, associada aos altos percentuais de dias de afastamento edeeventos, $19 \%$ e $15 \%$, respectivamente, pode-senotar a importância queeles têm entreos trabalhadores da instituição. Essegrupamento de morbidades apresentou aumento no número de ocorrências, em que pese à queda no número médio de dias de afastamento, mostrando sua ten dência decrescimento ecada vez mais se apresentando como distúrbios vinculados ao trabaIho, principalmente da forma como ele é organizado ${ }^{23}$. No meio bancário, existea necessidade de novas pesquisas, além de aprofundamento daquelasjá existentes, a fim detornar possível a busca de alternativas para os graves problemas de saúde ligados ao trabalho, principalmente os mentais e as lesões por esforço repetitivo ${ }^{16}$.

As diferenças apresentadas entre as duas morbidades mais importantes para esse grupo de trabalhadores bancários reforçam que pode estar havendo mudança no perfil de adoecimento, em que o grupamento dos transtornos mentais e do comportamento está aumentando, enquanto o grupamento das doenças osteomusculares está se reduzindo.

\section{Conclusões}

O levantamento do perfil de absenteísmo nessa empresa estatal do setor bancário mostrou-se importante para elucidação de alguns comportamentos referentes ao absenteísmo. Alguns dos itens levantados, como os referentes aos dados sociodemográficos, revelaram o envelhecimento da população trabalhadora, provavelmente decorrente da política restritiva de contratações e dos planos de adequação de quadros. Notou-se, ainda, crescimento no número de trabal hadores do sexo feminino, bem como dos níveis de escolaridade dos trabalhadores.

Quanto aosindicadores deabsenteísmo, houve aumento no número de afastamentos e redução na média de dias de afastamento.

Apesar dos afastamentos por doenças osteomusculares e do tecido conjuntivo predominarem no período analisado, no ano de 2003, prevaleceram os afastamentos por transtornos mentais e comportamentais. Estes, além do aumento da prevalência, apresentaram também elevação no número de eventos, bem como da representação percentual anual do número de dias de afastamentos, indicando tendência à mudança histórica no perfil de adoecimento na empresa.

Conclui-se, também, que as duas morbidades que mais afetaram os trabal hadores da empresa são aquelas tidas como ligadas às formas como o trabalho se organiza. Esse fato reforça a necessidade de um detal hamento do estudo atual no sentido de se investigarem as relações de determinação entre a organização do trabalho e as morbidades prevalentes observadas no banco pesquisado. 


\section{Colaboradores}

LS Silva foi responsável pela concepção, pesquisa, metodologia e redação. TM M Pinheiro foi responsável pela orientação da pesquisa e redação e E Sakurai, pela co-orientação da pesquisa.

\section{Referências}

1. M endes R, Dias EC. Saúde dos trabalhadores. In: Rouquayrol MZ, Almeida Filho N, organizadores. Epidemiologia \& Saúde. Rio de Janeiro: M edsi; 1999. p. 431-456.

2. DIEESE. Linha Bancários. M udanças no perfil da categoria bancária: O cupação, gênero, escolaridadeefaixa etária. Brasília: DIEESE; 1997.

3. Silva LS. Perfil do absenteísmo em um banco estatal em M inas Gerais: análise no período 1998 a 2003 [dissertação de mestrado]. Belo Horizonte (MG): Universidade Federal de M inas Gerais; 2005.

4. Segnini LRP. Reestruturação produtiva nos bancos no Brasil: desemprego, subcontratação e intensificação do trabalho. Rev. Educação \& Sociedade 1999; 10(67):183-209.

5. Jinkings $N$. Trabalho e resistência na fonte misteriosa. Os bancários no mundo da eletrônica e do dinheiro. Campinas: Unicamp; 2002.

6. Godoy SCB. Procura pelo serviço de atenção à saúde do trabalhador e absenteísmo-doença em hospital universitário. Rev M in Enferm 2001; 5(1/2):73-81.

7. Brasil. Ministério da Saúde. Representação no Brasil da OPAS/OMS. Doenças relacionadas ao trabaIho: manual de procedimentos para os serviços de saúde. Brasília: Ministério da Saúde; 2001.

8. Oficina Internacional del Trabajo (OIT). Enciclopedia de Salud. Seguridad e Higiene en el Trabajo. Madrid: Centro de Publicaciones del Ministerio de Trabajo y Seguridad Social; 1991.

9. Organização Mundial da Saúde. Classificação internacional de doenças e problemas relacionados à saúde. 10a revisão. São Paulo: Edusp; 1995.

10. Nogueira DP, Azevedo CAB. Absenteísmo-doença em mulheres. Rev Br Saúde Ocupac. 1982; 10:48-51.

11. M arcondes BW, Rotenberg L, Portela LF, Moreno CRC. 0 peso do trabalho "leve" feminino à saúde. São Paulo em perspectiva 2003; 17(2):91-101.

12. Lopes MJM, Leal SM C. A feminização persistente na qualificação profissional da enfermagem brasileira. Cadernos Pagu 2005; 24:105-125.

13. Danatro D. Ausentismo laboral de causa médica en una institución pública. Rev M éd U ruguai 1997; 13(2):101-109.

14. Belem JHR, Gaidzinski RR. Estudo das ausências da equipe de enfermagem. Rev Br Enferm 1998; 51(4):697-708.
15. Lund T, Labriola M, Christensen KB, Bültmann U, Villadsen E. Physical work environment risk factors for long term sickness absence: prospective findings among a cohort of 5357 employees in Denmark. BM J 2006; 332(7539):449-452.

16. Lima MEA. Reestruturação produtiva e seus impactos na qualidade de vida dos bancários. In: Anais do Simpósio Saúde M ental e Trabalho Bancário; 1997; Vitória.

17. Arola $\mathrm{H}$, Pitkänen $\mathrm{M}, \mathrm{N}$ ygard $\mathrm{C} .-\mathrm{H}, \mathrm{H}$ uhtala $\mathrm{H}$, M anka M.-L. The connection between age, job control and sickness absences among Finnish food workers. O ccupational M ed. 2003; 53(3):229-230.

18. Instituto Datafolha. Perfil do bancário. São Paulo: Instituto Datafolha/CNB/CUT; 1996.

19. Fischer FM. Retrospective study regarding absenteeism among shiftworkers. Arch Occup Environ Heath 1986; 58(4):301-320.

20. Valtorta A, Sidi E, Bianchi SC. Estudo do absenteísmo médico num hospital de grande porte. Rev $\mathrm{Br}$ Saúde Ocupac 1985; 13(51):55-61.

21. Muntaner $C$, Yong $L$, Xiaonan $X$, Thompson $T$, O'Campo P, Chung H, Eaton WW. County level socioeconomic position, work organization and depression disorder: a repeated measures cross-classified multilevel analysis of low-income nursing home workers. Health Place 2006; 12(4):688-700.

22. Ribeiro HP. A violência oculta no trabalho: as lesões por esforços repetitivos. 20a. ed. Rio de Janeiro: Fiocruz; 1999.

23. Campello MA, Weiser SR, Nordin M, Hiebert R. Work retention and nonspecific low back pain. Spine 2006; 31(16):1850-1857.

24. Feuerstein M, Nicolas RA. Development of a short form of the workstyle measure. O ccup. M ed. 2006; $56(2): 94-99$

Artigo apresentado em 11/08/2006

Aprovado em 25/09/2006

Versão final apresentada em 07/11/2006 